\title{
Antimicrobial use and antimicrobial susceptibility in Escherichia coli on small- and medium-scale pig farms in north-eastern Thailand
}

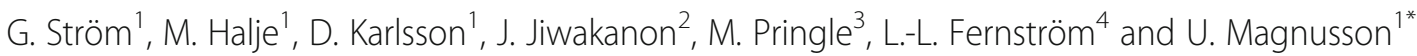

\begin{abstract}
Background: Intensification of livestock production seen in many low- and middle-income countries is often believed to be associated with increased use of antimicrobials, and may hence contribute to the emergence of antimicrobial resistance. The aim of this study was to map antimicrobial use on small- $(n=25)$ and medium-scale $(n=27)$ pig farms in north-eastern Thailand, and to compare antimicrobial susceptibility of commensal Escherichia coli isolated from sows on these farms.
\end{abstract}

Methods: Information regarding pig husbandry and antimicrobial treatment regimens was obtained by the use of semi-structured questionnaires. Faecal samples were collected from three healthy sows at each farm, and Escherichia coli was cultured and analysed for antimicrobial susceptibility using the broth microdilution method. Multilevel regression models were used to compare antimicrobial susceptibility between isolates from small- and medium-scale farms.

Results: All farms included in the study administered antimicrobials to their sows. Small-scale farmers most commonly (64\%) decided themselves when to give antimicrobials and the majority (60\%) bought the medicines at the local store or pharmacy, whereas farmers on medium-scale farms always discussed antimicrobial treatment with a veterinarian. Medium-scale farms used a greater diversity of antimicrobials than small-scale farms and did also administer antimicrobials in feed to a higher extent. High levels of antimicrobial resistance to several critically important antimicrobials for human medicine (including ciprofloxacin, streptomycin and ampicillin) were found in isolates from both small- and medium-scale farms. Resistance levels were significantly $(P<0.05)$ higher in isolates from medium-scale farms for several of the antimicrobials tested, as well as the level of multidrug-resistance $(P=0.026)$.

Conclusion: The routines regarding access and administration of antimicrobials differed between the small- and medium-scale farms. Although the level of antimicrobial resistance, as well as multidrug-resistance, was higher in isolates from medium-scale farms, it cannot be concluded if this increase is a consequence of a more abundant use of antimicrobials, or a result of differences in administration routines.

Keywords: Antimicrobial use, Antimicrobial resistance, E. coli, Pig production, Farm size, Thailand

\footnotetext{
* Correspondence: ulf.magnusson@slu.se

1 Department of Clinical Sciences, Swedish University of Agricultural Sciences,

Uppsala, Sweden

Full list of author information is available at the end of the article
} 


\section{Background}

The emergence of antimicrobial resistance (AMR) has become a serious global health concern, and imprudent use of antimicrobials has been recognized as a contributing factor in the selection for resistant bacterial populations [1]. Although much of the resistance seen in human medicine originates from inappropriate use in humans [2], antimicrobial use within the livestock sector is believed to contribute to AMR through increased selective pressure and through generating resistance reservoirs [3, 4].

The level of AMR has been shown to be highest in low- and middle-income countries, particularly those in South and Southeast Asia [5]. In Thailand, infections with antimicrobial resistant bacteria in humans have been estimated to be the cause of almost 90,000 hospitalisations and 38,000 mortalities each year [6], and high levels of resistance have been documented in the environment and along the food production chain [7].

As Escherichia coli are intestinal commensal bacteria present in both animals and humans, and therefore subjected to a high selection pressure driven by the antimicrobials to which their hosts are exposed, they may serve as a good indicator to monitor the general level of AMR in a human or livestock population [8]. Also, although commensal bacteria are normally harmless, they may constitute a reservoir of resistance genes that may be transmitted to pathogenic bacteria [9].

Today's intensive livestock production often depends on antimicrobials to maintain the health and productivity of the livestock [10]. Antimicrobials are not only used to treat infectious diseases, but are also sometimes used subtherapeutically for growth promotion, a practice associated with a high potential for selection of resistant pathogens [11]. Intensification of livestock production in many lowand middle-income countries, as exemplified by Thailand's pig sector $[12,13]$, is often believed to be driving an increased use of antimicrobials and thereby also an increased emergence of AMR [10, 14]. Here we explored the validity of that assertion in a country with an expanding pig sector. We therefore investigated antimicrobial use on small- and medium-scale pig farms in north-eastern Thailand, and compared antimicrobial susceptibility of commensal $E$. coli isolated from sows on these farms.

\section{Methods}

\section{Study area}

This cross-sectional study was conducted on small- and medium-scale pig farms situated near the city Khon Kaen in north-eastern Thailand. In 2013, the country produced more than 16 million pigs for slaughter [12]. Among the 220,000 households that raised pigs, 94\% raised less than 50 pigs per year. On the other hand, two large companies owned about $46 \%$ of all breeder pigs. Currently, there are about 200 such contractual, company-owned pig farms in the Khon Kaen province and the density of the total number of pigs, as well as small - scale farms (less than 50 heads per farm), are about the averages for the provinces in Thailand [13]. In the last decade, Thailand's pig sector has intensified and farm sizes have increased; a trend that is expected to continue [13].

\section{Study design and data collection}

The study was conducted between September and November 2015. Inclusion criteria for small-scale farms were that the farm kept sows for breeding, with a maximum of 20 sows, whereas medium-scale farms were defined as farms with between 100 and 500 sows, a classification relating to previous work in Thailand where such farms have been named "smallholders" and "small largescale farms", respectively [13]. In order to make a distinct difference in size between the small- and medium-scale farms in the present study, no farms with 21-99 sows were included. From a governmental list of villages with pig farm(s), the heads in randomly selected villages were contacted for checking that there were pig farms at the time of the fieldwork. The villages with positive responses were visited and all farms where the farmers were at home agreed to participate. For the medium-scale farms, that all but one belonged to two companies, the company officers were asked to make a choice of farms to be equally distributed over the province. By this procedure, 25 small-scale and 27 medium-scale farms were included in the study.

A faecal sample was collected, using a rectal swab, from the individual pen of three randomly chosen healthy sows at each farm and added to sterile plastic tubes containing Amies medium. At the small-scale farms, sampling was performed by the authors ( $\mathrm{MH}, \mathrm{DK})$, and at the mediumscale farms by local veterinary assistants who were thoroughly instructed beforehand how to collect the samples in a correct manner. Sampling was performed at mid-day and samples were transported to Khon Kaen University within $1-6 \mathrm{~h}$ and stored at $2-8{ }^{\circ} \mathrm{C}$ until analysis, which was performed within $48 \mathrm{~h}$ after sampling. Because not all small-scale farms had three healthy sows, only 69 samples were obtained from these farms.

A semi-structured questionnaire, with questions on farm characteristics, pig husbandry and routines for antimicrobial treatment, was administered to the person responsible for the pigs at each farm. The questionnaire was in English and had been pre-tested on pig farms not involved in the subsequent study, after which necessary adjustments were made. Interviews were performed by the authors $\mathrm{MH}$ and $\mathrm{DK}$ together with a Thai speaking veterinary student at the Khon Kaen University who translated the questions to Thai and the farmer's answers to English. The interviews took about $40 \mathrm{~min}$ each. 


\section{Antimicrobial susceptibility testing}

Each faecal sample was streaked on MacConkey agar and incubated at $44{ }^{\circ} \mathrm{C}$ overnight. Suspected E. coli isolates were sub-cultured on blood agar, incubated at $37^{\circ} \mathrm{C}$ overnight and tested for production of tryptophanase (indole). One indole positive isolate was selected from each faecal sample and further tested for antimicrobial susceptibility.

Susceptibility testing was performed by broth microdilution, using the growth method inoculum preparation, according to the standards described by the Clinical and Laboratory Standards Institute (CLSI) [15]. Microdilution panels (VetMIC GN-mo, National Veterinary Institute, Uppsala, Sweden) were used to determine susceptibility to 13 antimicrobials (ciprofloxacin, nalidixid acid, gentamicin, streptomycin, tetracycline, florfenicol, chloramphenicol, colistin, sulfamethoxazole, trimethoprim, ampicillin, cefotaxime, ceftazidime). Escherichia. coli ATCC 25922 was used as quality control strain.

The Minimum Inhibitory Concentration (MIC) for each antimicrobial was recorded and epidemiological cut-off values (ECOFFs), defined by the European Committee on Antimicrobial Susceptibility Testing [16], were used to differentiate between wild-type and non-wild-type isolates. Wild-type and non-wild-type isolates will henceforth be referred to as susceptible and resistant, respectively. Multidrug-resistance was defined as isolates resistant to at least three different categories (i.e. with different mechanisms of action) of the antimicrobials tested [17].

\section{Statistical analyses}

Statistical analyses were conducted in SAS software 9.4 (SAS Institute Inc., Cary, NC). Descriptive statistics were computed to define farm characteristics. To investigate associations between management factors, such as use of antimicrobials and veterinary services, and resistance against different types of antimicrobials, univariable logistic regression and Fisher's exact test were used where applicable. Multilevel regression models were used to compare susceptibility patterns between the small- and medium-scale farms. As isolates from the same farm were assumed to be more alike, generalised estimating equations (GEE) were used to account for the effect of clustering within farms. The statistical significance level was defined as a two-tailed $P$-value $<0.05$.

\section{Results}

\section{Farm characteristics}

At the small-scale farms, all privately owned, the number of sows varied from 1 to 19 , with a median of 5 sows $\left(25^{\text {th }}\right.$ and $95^{\text {th }}$ percentiles: 3 and 12 sows). Most of these farms (60\%) practised a 'farrow-to-finish' system, where pigs were raised from birth to slaughter. The rest of the small-scale farms were either breeding farms $(28 \%)$, where the piglets were sold to other farmers after weaning, or farms that practised a combination of the two systems (12\%).

The medium-scale farms in this study, except for one farm that was privately owned and managed, were contract farms contracted by two different companies. The number of sows ranged from 100 to 400 , with a median number of 210 sows $\left(25^{\text {th }}\right.$ and $95^{\text {th }}$ percentiles: 155 and 327 sows). All medium-scale farms were breeding farms, and the privately managed farm also combined this with a 'farrow-to-finish' system.

None of the farms in this study kept their pigs freely roaming; instead the pigs were kept in enclosures, such as concrete pens or metal crates.

\section{Antimicrobial use}

All farms in this study administered antimicrobials to their sows, though only 21 of the 25 small-scale farms knew the names of the antimicrobials used. Small-scale farmers most commonly decided themselves when to give antimicrobials and the majority bought the drugs at the local store or pharmacy (Table 1). On all mediumscale farms, the farmer discussed with a veterinarian when to give antimicrobials to the animals, and the contract farms received the antimicrobials through their respective contracting company. The privately managed mediumscale farm received antimicrobials through a pharmaceutical company. Furthermore, antimicrobials were added to the feed on all medium-scale farms, a practice that was performed on only one of the small-scale farms.

The number and types of antimicrobials used differed between small- and medium-scale farms (Table 2). Penicillin and streptomycin were used as injectable drugs on all the medium-scale farms, compared to only $19 \%$ of the smallscale farms. Small-scale farms most commonly used amoxicillin $(38 \%)$ and enrofloxacin (57\%) as injectable drugs. For the contract farms, the two contracting companies had

Table 1 Practices related to use and access to antimicrobials on the small- and medium-scale pig farms

\begin{tabular}{|c|c|c|}
\hline & $\begin{array}{l}\text { Small-scale \% } \\
\quad(n=25)\end{array}$ & $\begin{array}{c}\text { Medium-scale \% } \\
\quad(n=27)\end{array}$ \\
\hline $\begin{array}{l}\text { Antimicrobials injected for disease } \\
\text { treatment }\end{array}$ & $100(25)$ & $100(27)$ \\
\hline $\begin{array}{l}\text { Antimicrobials added to, or included in, } \\
\text { feed }^{\text {a }}\end{array}$ & $4(1)$ & $100(27)$ \\
\hline \multicolumn{3}{|c|}{ Person who decides on when to give antimicrobials } \\
\hline Farmer & $68(17)$ & $0(0)$ \\
\hline Veterinarian & $32(8)$ & $100(27)$ \\
\hline \multicolumn{3}{|l|}{ Source of antimicrobials } \\
\hline From veterinarian & $32(8)$ & $0(0)$ \\
\hline From local store/pharmacy & $60(15)$ & $0(0)$ \\
\hline From the contracting company & $4(1)$ & $96(26)$ \\
\hline Other & $4(1)$ & $4(1)$ \\
\hline
\end{tabular}

${ }^{\mathrm{a} O n}$ regular basis 


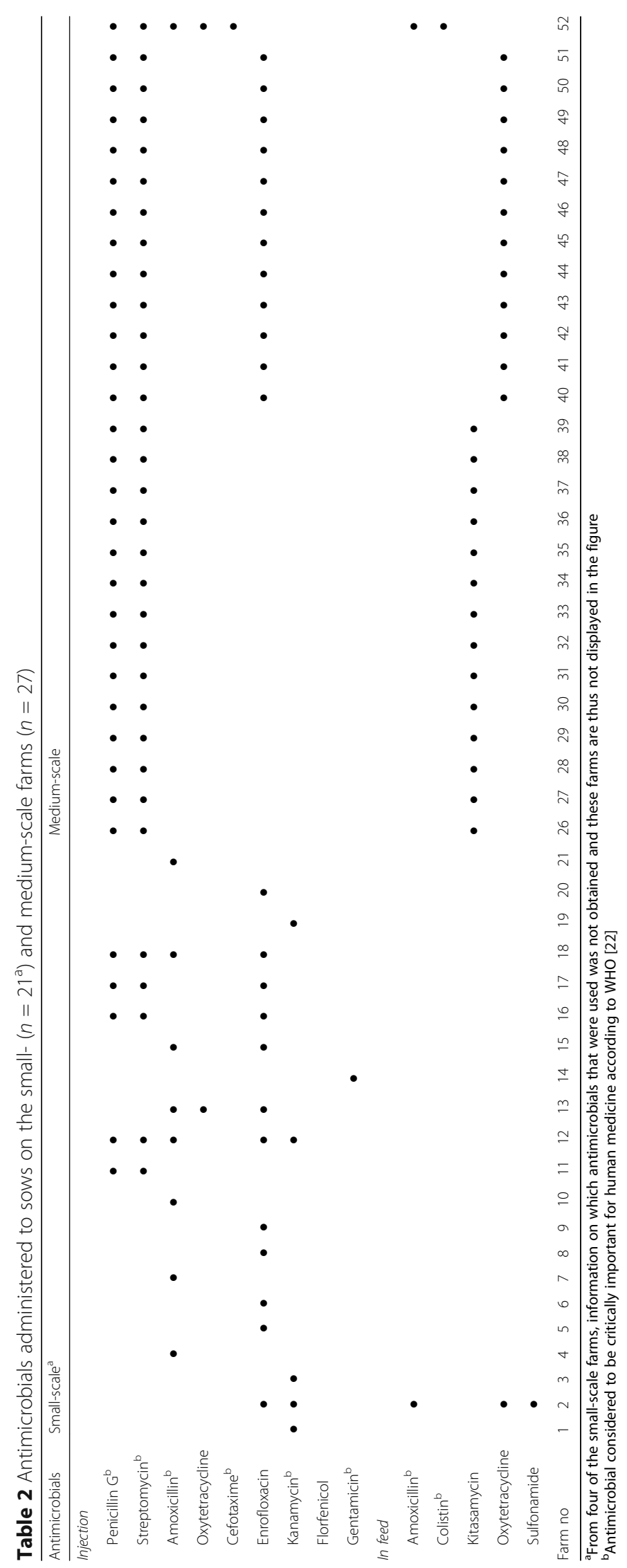


different regimes regarding treatment with antimicrobials. Both companies provided penicillin and streptomycin as injectable drugs to their contract farms, and one of the companies also provided enrofloxacin. The companies either provided kitasamycin or oxytetracycline as in-feed antimicrobials to their respective farms. On the privately managed medium-scale farm, penicillin, streptomycin, amoxicillin, oxytetracycline and cefotaxime were administered by injection, and amoxicillin and colistin were provided with the feed. Unfortunately, no information regarding the amount of antimicrobials used could be obtained in this study.

\section{Antimicrobial susceptibility}

In total, 69 and 81 isolates were obtained from the smalland medium-scale farms, respectively. Around 90\% (62/ 69) of isolates from the small-scale farms showed resistance to at least one category of antimicrobials. The corresponding figure for medium-scale farms was $98 \%$ (79/81). The MIC distributions for isolates from the small- and medium-scale farms are presented in Tables 3 and 4, respectively.

For both small- and medium-scale farms, most isolates showed resistance to ampicillin, tetracycline and sulfamethoxazole, ranging from $61 \%$ to $86 \%$ (for details see Table 5). No isolates showed resistance to colistin, and only a few isolates were resistant to the third generation cephalosporins cefotaxime and ceftazidime. Isolates obtained from medium-scale farms were significantly more likely to be resistant to streptomycin $(P<0.001)$, sulfamethoxazole $(P=0.006)$, trimethoprim $(P<0.001)$ and chloramphenicol $(P=0.023)$, compared to isolates from small-scale farms. Multidrug-resistance was more common $(P=0.026)$ in isolates from medium-scale farms (89\%), than in isolates from small-scale farms (74\%).

Isolates obtained from farms that used enrofloxacin were more likely to show resistance to ciprofloxacin $(P=0.02)$, but not to nalidixic acid $(P=0.47)$. Moreover, all isolates from medium-scale farms that administered oxytetracycline in the feed were resistant to tetracycline.

\section{Discussion}

The overall aim of this study was to investigate possible differences in antimicrobial use in pigs on small- and medium-scale pig farms in Thailand, a country that is experiencing an intensification of the pig sector, like other countries in the region [13]. Furthermore, we compared antimicrobial susceptibility of isolates of $E$. coli from pigs on these farms. This research question stems from the common assertion that farm intensification, in particular in the pig and poultry sectors, is associated with a more abundant use of antimicrobials, and thereby also with higher levels of antimicrobial resistance (AMR) [10, 14].
The levels of AMR presented here are largely similar to those in previous studies on $E$. coli isolated from animals in Southeast Asia, according to a recent review by Nhung et al. [18]. The highest frequencies of resistance in isolates from both small- and medium-scale farms were found against tetracycline, followed by ampicillin. Multidrug-resistance was significantly more commonly observed in isolates from pigs on medium- compared to small-scale farms. These results are in accordance with a study by Love et al. [19], where herd size was reported to be positively associated with higher rates of multidrugresistance in $E$. coli isolated on pig farms in northern Thailand. Although the medium-scale farms in the present study routinely used a greater diversity of antimicrobials, we do not have any reliable information regarding the amounts of antimicrobials used on the farms. Therefore, no associations between the amounts of administrated antimicrobials and AMR can be determined here.

Penicillin and streptomycin were used on all mediumscale farms, whereas small-scale farms most commonly used enrofloxacin and amoxicillin. Enrofloxacin was also used on almost half of the medium-scale farms. Although this antimicrobial is not used in human medicine, being a quinolone its use in animals selects for resistance to other quinolones that are used for humans. Here we found a positive association between the use of enrofloxacin on the farm and ciprofloxacin resistance in isolates of $E$. coli from the pigs, which indicates the importance of restricting the use of quinolones in animal agriculture. These results are in accordance with studies conducted on pig and chicken farms in Vietnam [20,21].

Many of the antimicrobials used by the farms in this study are classified by the World Health Organization (WHO) as critically important for human medicine [22], including amoxicillin, cefotaxime and colistin. The recent discovery of the plasmid mediated $m c r-1$ gene in bacteria isolated from pigs [23], a gene that confers resistance to colistin and that may be transferred horizontally between bacteria, has emphasised the importance of colistin as a last-resort antimicrobial that should possibly be restricted to human use. Plasmid-mediated colistin resistance has since been detected in almost all regions of the world [24], including in bacteria isolated from Vietnamese pigs $[20,25]$. None of the isolates in the present study, however, were resistant to colistin, and it was only used on one of the study farms.

Data presented in this study indicate that medium-scale farms administer antimicrobials to the feed to a higher extent than small-scale farms. Oral administration of antimicrobials is known to increase AMR in E. coli from pigs [26]. A possible explanation to the higher use of antimicrobials in feed on the medium-scale farms in this study could be that these farms experience an increased disease pressure that is associated with larger group sizes and 
Table 3 Resistance and distributions of Minimum Inhibitory Concentrations (MIC) for E. coli isolates from small-scale farms

\begin{tabular}{|c|c|c|c|c|c|c|c|c|c|c|c|c|c|c|c|c|c|c|c|c|}
\hline \multirow[t]{2}{*}{ Antimicrobial } & \multirow{2}{*}{$\begin{array}{l}\text { Resistance } \\
(\%)\end{array}$} & \multicolumn{19}{|c|}{ Distributions (\%) of MICs (mg/L) } \\
\hline & & $\leq 0.008$ & 0.016 & 0.03 & 0.06 & 0.12 & 0.25 & 0.5 & 1 & 2 & 4 & 8 & 16 & 32 & 64 & 128 & 256 & 512 & 1024 & $>1024$ \\
\hline Ciprofloxacin & 40.5 & & 1.4 & 18.8 & 39.1 & 2.9 & 5.8 & 10.1 & 8.7 & 13 & & & & & & & & & & \\
\hline Nalidixic acid & 20.2 & & & & & & & & & 8.7 & 46.4 & 20.3 & 4.3 & 7.2 & & 2.9 & 10.1 & & & \\
\hline Gentamicin & 11.4 & & & & & & 7.2 & 36.2 & 34.8 & 10.1 & 4.3 & & 1.4 & 1.4 & 4.3 & & & & & \\
\hline Streptomycin & 37.6 & & & & & & & & & $\underline{7.2}$ & 17.4 & 21.7 & 15.9 & 10.1 & 1.4 & 14.5 & 2.9 & 8.7 & & \\
\hline Tetracycline & 75.3 & & & & & & & & $\underline{2.9}$ & 11.6 & 7.2 & 2.9 & 8.7 & 30.4 & 30.4 & 5.8 & & & & \\
\hline Florfenicol & 14.5 & & & & & & & & & & $\underline{5.8}$ & 62.3 & 17.4 & & 14.5 & & & & & \\
\hline Chloramphenicol & 39.1 & & & & & & & & & & $\underline{20.3}$ & 37.7 & 2.9 & 21.7 & 17.4 & & & & & \\
\hline Colistin & 0 & & & & & & & $\underline{73.9}$ & 14.5 & 11.6 & & & & & & & & & & \\
\hline Sulfamethoxazole & 60.8 & & & & & & & & & & & $\underline{26.1}$ & 10.1 & 2.9 & & & & 1.4 & & 59.4 \\
\hline Trimethoprim & 42 & & & & & & 4.3 & 36.2 & 15.9 & 1.4 & & & & 42 & & & & & & \\
\hline Ampicillin & 69.6 & & & & & & & & $\underline{8.7}$ & 20.3 & 1.4 & & & & & 2.9 & 66.7 & & & \\
\hline Cefotaxime & 1.4 & & & $\underline{15.9}$ & 66.7 & 14.5 & 1.4 & & & & 1.4 & & & & & & & & & \\
\hline Ceftazidime & 4.3 & & & & & 13 & 66.7 & 15.9 & 2.9 & & & 1.4 & & & & & & & & \\
\hline
\end{tabular}

White fields denote range of dilutions tested for each substance. MICs higher than the highest concentration tested are given as the concentration closest above the range. MICs equal to or lower than the lowest concentration tested are presented underlined. The ECOFF [16] for each substance is presented as a vertical line

higher densities of animals [27], or simply that these farms were more commercially oriented and therefore pursued better animal performance and higher returns from production. We do not have information whether these antimicrobials were intended to promote growth or to prevent sickness in the animals, therefore these are only speculations. However, Thailand recently, as the first country in the region, banned the inclusion of antimicrobials as growth promotors in animal agriculture
[28], which is an important step towards a more prudent use of antimicrobials.

We found a difference between the ways in which small- and medium-scale farms accessed antimicrobials, where the latter always consulted a veterinarian before treating sick animals. This difference, that must be interpreted with caution given the sample size, might however not be resulting from increased farm size, but could merely be a consequence of that the medium-scale farms

Table 4 Resistance and distributions of Minimum Inhibitory Concentrations (MIC) for E. coli isolates from medium-scale farms

\begin{tabular}{|c|c|c|c|c|c|c|c|c|c|c|c|c|c|c|c|c|c|c|c|c|}
\hline \multirow[t]{2}{*}{ Antimicrobial } & \multirow{2}{*}{$\begin{array}{l}\text { Resistance } \\
(\%)\end{array}$} & \multicolumn{19}{|c|}{ Distributions (\%) of MICs (mg/L) } \\
\hline & & $\leq 0.008$ & 0.016 & $\mathbf{0 . 0 3}$ & 0.06 & 0.12 & 0.25 & 0.5 & 1 & 2 & 4 & 8 & 16 & 32 & 64 & 128 & 256 & 512 & 1024 & $>1024$ \\
\hline Ciprofloxacin & 48.1 & & & 9.9 & 42 & 4.9 & 4.9 & 23.5 & 6.2 & 8.6 & & & & & & & & & & \\
\hline Nalidixic acid & 30.8 & & & & & & & & & 14.8 & 35.8 & 14.8 & 3.7 & 1.2 & 1.2 & 4.9 & 23.5 & & & \\
\hline Gentamicin & 7.4 & & & & & & $\underline{1.2}$ & 29.6 & 51.9 & 9.9 & 3.7 & & 1.2 & & 2.5 & & & & & \\
\hline Streptomycin & 76.5 & & & & & & & & & & 3.7 & 4.9 & 14.8 & 27.2 & 14.8 & 13.6 & 8.6 & 12.3 & & \\
\hline Tetracycline & 86.3 & & & & & & & & $\underline{2.5}$ & 3.7 & 3.7 & 3.7 & 12.3 & 22.2 & 37 & 14.8 & & & & \\
\hline Florfenicol & 2.4 & & & & & & & & & & 7.4 & 38.3 & 51.9 & 1.2 & 1.2 & & & & & \\
\hline Chloramphenicol & 58 & & & & & & & & & & $\underline{9.9}$ & 21.0 & 11.1 & 45.7 & 12.3 & & & & & \\
\hline Colistin & 0 & & & & & & & $\underline{75.3}$ & 19.8 & 4.9 & & & & & & & & & & \\
\hline Sulfamethoxazole & 84 & & & & & & & & & & & $\underline{6.2}$ & 8.6 & 1.2 & & & & & & 84.0 \\
\hline Trimethoprim & 70.4 & & & & & & 6.2 & 18.5 & 4.9 & & & & & 70.4 & & & & & & \\
\hline Ampicillin & 85.2 & & & & & & & & $\underline{4.9}$ & 8.6 & 1.2 & & & & & 2.5 & 82.7 & & & \\
\hline Cefotaxime & 1.2 & & & $\underline{7.4}$ & 56.8 & 33.3 & 1.2 & & & & 1.2 & & & & & & & & & \\
\hline Ceftazidime & 3.7 & & & & $\underline{1.2}$ & 1.2 & 66.7 & 27.2 & 2.5 & & & 1.2 & & & & & & & & \\
\hline
\end{tabular}

White fields denote range of dilutions tested for each substance. MICs higher than the highest concentration tested are given as the concentration closest above the range. MICs equal to or lower than the lowest concentration tested are presented underlined. The ECOFF [16] for each substance is presented as a vertical line 
Table 5 Antimicrobial resistance parameters of E. coli isolates from pigs on the small- and medium-scale farms

\begin{tabular}{|c|c|c|c|c|}
\hline \multirow[t]{2}{*}{ Antimicrobial } & \multicolumn{2}{|c|}{ Resistant isolates \% (n) } & \multirow[t]{2}{*}{$P$-value } & \multirow{2}{*}{$\begin{array}{c}\text { OR } \\
(95 \% \mathrm{Cl})^{\mathrm{a}}\end{array}$} \\
\hline & Small-scale $(n=69)$ & Medium-scale $(n=81)$ & & \\
\hline Ciprofloxacin $^{\dagger}$ & $41(28)$ & $48(39)$ & 0.54 & \\
\hline Nalidixic acid ${ }^{\dagger}$ & $20(14)$ & $31(25)$ & 0.21 & \\
\hline Gentamicin $^{+}$ & $11(8)$ & $7(6)$ & 0.39 & \\
\hline Streptomycin ${ }^{\dagger}$ & $38(26)$ & $77(62)$ & $<0.001$ & $5.4(2.7-11)$ \\
\hline Tetracycline & $75(52)$ & $86(70)$ & 0.09 & $2.1(0.9-4.8)$ \\
\hline Florfenicol & $14(10)$ & $2(2)$ & 0.01 & $0.1(0.03-0.7)$ \\
\hline Chloramphenicol & $39(27)$ & $58(47)$ & 0.02 & $2.2(1.1-4.1)$ \\
\hline Colistin $^{+}$ & $0(0)$ & $0(0)$ & - & - \\
\hline Sulfamethoxazole & $61(42)$ & $84(68)$ & 0.002 & $3.4(1.6-7.2)$ \\
\hline Trimethoprim & $42(29)$ & $70(57)$ & $<0.001$ & $3.3(1.7-6.4)$ \\
\hline Ampicillin $^{\dagger}$ & $70(48)$ & $85(69)$ & 0.02 & $2.5(1.1-5.6)$ \\
\hline Cefotaxime $^{\dagger}$ & $1(1)$ & $1(1)$ & 0.9 & \\
\hline Ceftazidime $^{\dagger}$ & $4(3)$ & $4(3)$ & 0.8 & \\
\hline Multidrug-resistance ${ }^{b}$ & $74(51)$ & $89(72)$ & 0.002 & $3.7(1.2-8.8)$ \\
\hline
\end{tabular}

${ }^{\dagger}$ Antimicrobial classified as critically important for human medicine according to WHO [22]

${ }^{a}$ For the OR estimates, the small-scale farms were used as reference variable and GEE models were used to account for clustering of isolates within farms

${ }^{\mathrm{b}}$ Multidrug-resistance defined as an isolate resistant against at least three different categories of the antimicrobial agents tested

were bound to the routines of the contracting companies, as this was the case for all but one of the medium-scale farms. The two contracting companies, owning about half each of the medium-scale farms in the current study, are very large companies that have operations all over the country, and one may thus assume that the regimes regarding antimicrobial treatment presented here are representative for many medium-scale farms in Thailand.

In this study the emphasis was on antimicrobial use and susceptibility in commensal E. coli collected from sows. Sows were sampled as antimicrobial use and resistance in $E$. coli from sows is of epidemiological importance within the herd, as the sow may serve as a reservoir of resistant bacteria and genetic determinants [29]. Whilst the recommendation by the European Food Safety Authority (EFSA) [30] is that samples should be taken from fattener pigs, the approach adopted here was to ensure sufficient number of pigs to sample at each farm, as small-scale farms might not have enough fatteners at the time of visit.

As already mentioned we found a positive association between enrofloxacin use and ciprofloxacin resistance, both being fluoroquinolones used in veterinary and human medicine, respectively. Our analyses also revealed some associations between the use of certain antimicrobials and AMR. Such associations should be interpreted with caution, especially since this study contained relatively few farms and the fact that we could not obtain reliable information from all farms regarding precise treatment regimes, e.g. duration and dosage. Thus, assessing possible associations between the treatment regime and antimicrobial resistance might fall outside the power of this study.

The data from the current study have been interpreted conservatively given the relatively small sample size. Another limitation to take into account when reading the paper is that the selection of farms might not be regarded as entirely random. The antimicrobial activity testing panel used is designed to detect resistance among $E$. coli, therefore there may be resistance in other bacterial species and to other antimicrobials not tested for in this study.

\section{Conclusions}

Considerable reservoirs of antimicrobial resistance were observed in E. coli from pigs on both small- and mediumscale farms in north-eastern Thailand. Higher rates of resistance, including multidrug-resistance, were observed on medium-scale farms, which could be a consequence of the greater diversity of antimicrobials used on these farms, as well as of the higher extent to which antimicrobials were administered in the feed. Although we found differences in how antimicrobials were accessed and administered between the small- and medium-scale farms, it cannot be concluded whether these differences could be responsible for the higher rate of antimicrobial resistance observed on the medium-scale farms.

\section{Abbreviations}

AMR: Antimicrobial resistance; CLSI: Clinical and laboratory standards institute; ECOFF: Epidemiological cut-off value; EFSA: European food safety authority; EUCAST: European Committee on Antimicrobial Susceptibility Testing; GEE: Generalised estimating equations; MIC: Minimum inhibitory concentration; SLU: Swedish University of Agricultural Sciences; WHO: World Health Organization 


\section{Acknowledgements}

The authors would like to express their gratitude towards the farmers that participated in the study, as well as the veterinary students who assisted during the fieldwork

\section{Funding}

Not applicable.

\section{Availability of data and materials}

Data are stored at the Swedish University of Agricultural Sciences (SLU), Sweden, and can be shared upon request.

\section{Authors' contributions}

Study design: UM, JK, MP, LF, MH, DK. Data collection and analysis: MH, DK, JK, MP, LF, GS. Manuscript writing: GS, MH, DK, UM. Manuscript review: All authors. All authors read and approved the final manuscript.

\section{Ethics approval and consent to participate}

All procedures performed in this study were in accordance with the ethical standards of the institutional and national research committee, and with the 1964 Helsinki declaration and its later amendments for non-sensitive data collected from humans. For collection of this kind of data ethical approval is exempted [31]. All participants were informed about the purpose of the study and that their participation was anonymous and on voluntary basis. Informed consent was obtained from each participant before the study was conducted. As the animal sampling procedure was non-invasive, no ethical approval was required.

\section{Consent for publication}

Not applicable.

\section{Competing interests}

The authors declare that they have no competing interest.

\section{Publisher's Note}

Springer Nature remains neutral with regard to jurisdictional claims in published maps and institutional affiliations.

\section{Author details}

'Department of Clinical Sciences, Swedish University of Agricultural Sciences, Uppsala, Sweden. ${ }^{2}$ Research Group for Preventive Technology in Livestock, Faculty of Veterinary Medicine, Khon Kaen University, Khon Kaen, Thailand. ${ }^{3}$ National Veterinary Institute, Uppsala, Sweden. ${ }^{4}$ Department of Biomedical Sciences and Veterinary Public Health, Swedish University of Agricultural Sciences, Uppsala, Sweden.

\section{Received: 1 March 2017 Accepted: 10 July 2017}

\section{Published online: 17 July 2017}

References

1. WHO. Antimicrobial resistance: global report on surveillance 2014. Geneva: World Health Organization; 2014

2. Aarestrup FM. Veterinary drug usage and antimicrobial resistance in bacteria of animal origin. Basic Clin Pharmacol Toxicol. 2005:96:271-81.

3. Smith DL, Harris AD, Johnson JA, Silbergeld EK, Morris JG Jr. Animal antibiotic use has an early but important impact on the emergence of antibiotic resistance in human commensal bacteria. Proc Natl Acad Sci U S A. 2002:99:6434-9.

4. van den Bogaard $A E$, Stobberingh EE. Epidemiology of resistance to antibiotics. Links between animals and humans. Int J Antimicrob Agents. 2000;14:327-35.

5. Kang $\mathrm{Cl}$, Song JH. Antimicrobial resistance in Asia: current epidemiology and clinical implications. Infect Chemother. 2013:45:22-31.

6. Phumart P, Phodha P, Thamlikitkul P, Riewpaiboon P, Prakongsai P. Health and economic impacts of antimicrobial resistant infections in Thailand: preliminary study. Journal of Health System Research. 2012;6:352-60.

7. Boonyasiri A, Tangkoskul T, Seenama C, Saiyarin J, Tiengrim S, Thamlikitkul V. Prevalence of antibiotic resistant bacteria in healthy adults, foods, food animals, and the environment in selected areas in Thailand. Pathog Glob Health. 2014;108:235-45
8. EFSA (European Food Safety Authority) and ECDC (European Centre for Disease Prevention and Control). EU Summary Report on antimicrobial resistance in zoonotic and indicator bacteria from humans, animals and food in 2013. EFSA J. 2015; doi:10.2903/j.efsa.2015.4036

9. Marshall BM, Ochieng DJ, Levy SB. Commensals: underappreciated reservoir of antibiotic resistance. Microbe. 2009:4:231-8.

10. Robinson TP, Bu DP, Carrique-Mas J, Fevre EM, Gilbert M, Grace D, Hay SI, Jiwakanon J, Kakkar M, Kariuki S, Laxminarayan R, Lubroth J, Magnusson U, Thi Ngoc P, Van Boeckel TP, Woolhouse MEJ. Antibiotic resistance: mitigation opportunities in livestock sector development. Animal. 2017;11:1-3.

11. Hughes P, Heritage J. Antibiotic Growth-Promoters in Food Animals. Assessing Quality and Safety of Animal Feeds. FAO Animal Production and Health Papers Series No 160. Rome: Food and Agriculture Organization of the United Nations; 2004. pp. 129-152.

12. Tantasuparuk W, Kunavongkrit A. Pig production in Thailand. In: Country report. 2014; 2014

13. Thanapongtharm W, Linard C, Chinson P, Kasemsuwan S, Visser M, Gaughan AE, Epprech M, Robinson TP, Gilbert M. Spatial analysis and characteristics of pig farming in Thailand. BMC Vet Res. 2016;12:218.

14. Van Boeckel TP, Brower C, Gilbert M, Grenfell BT, Levin SA, Robinson TP, Teillant A, Laxminarayan R. Global trends in antimicrobial use in food animals. Proc Natl Acad Sci U S A. 2015;112:5649-54.

15. CLSI (Clinical and Laboratory Standards Institute. Performance standards for antimicrobial disk and dilution susceptibility tests for bacteria isolated from animals; approved standard. In: CLSI document VET01-A4. Forth ed. Wayne, Pennsylvania, USA: Clinical and Laboratory Standards Institute.

16. EUCAST (European Committee on Antimicrobial Susceptibility Testing). MIC distributions and ECOFFs. 2016. http://mic.eucast.org/Eucast2/ SearchController/search.jsp?action=performSearch\&BeginIndex=0\&Micdif= mic\&Numberlndex=50\&Antib=-1\&Specium=162. Accessed 28 Dec 2016

17. Magiorakos AP, Srinivasan A, Carey RB, Carmeli Y, Falagas ME, Giske CG, Harbarth S, Hindler JF, Kahlmeter G, Olsson-Liljequist B, Paterson DL, Rice LB, Stelling J, Struelens MJ, Vatopoulos A, Weber JT, Monnet DL. Multidrugresistans, extensively drug-resistant and pandrug-resistant bacteria: an international expert proposal for interim standard definitions for aquired resistance. Clin Microbiol Infect. 2012;18:268-81.

18. Nhung NT, Cuong NV, Thwaites G, Carrique-Mas J. Antimicrobial usage and antimicrobial resistance in animal production in Southeast Asia: a review. Antibiotics. 2016:5:37.

19. Love DC, Tharavichitkul P, Arjkumpa O, Imanishi M, Hinjoy S, Nelson K, Nachman KE. Antimicrobial use and multidrug-resistant salmonella spp., Escherichia coli, and Enterococcus faecalis in swine from northern Thailand. Thai J Vet Med. 2015:45:43-53.

20. Nguyen NT, Nguyen HM, Nguyen CV, Nguyen TV, Nguyen MT, Thai QH, Ho MH, Thwaites G, Ngo HT, Baker S, Carrique-Mas J. Use of Colistin and other critical antimicrobials on pig and chicken farms in southern Vietnam and its association with resistance in Commensal Escherichia coli bacteria. Appl Environ Microbiol. 2016;82:3727-35.

21. Nguyen VT, Carrique-Mas J, Ngo TH, Ho HM, Ha TT, Campbell JI, Nguyen TN, Hoang NN, Pham VM, Wagenaar JA, Hardon A, Thai QH, Schultsz C. Prevalence and risk factors for carriage of antimicrobial-resistant Escherichia coli on household and small-scale chicken farms in the Mekong Delta of Vietnam. J Antimicrob Chemother. 2015;70:2144-52.

22. WHO. Critically important antimicrobials for human medicine - 3rd revision. Geneva: World Health Organization; 2012.

23. Liu YY, Wang Y, Walsh TR, Yi LX, Zhang R, Spencer J, Doi Y, Tian G, Dong B, Huang X, Yu LF, Gu D, Ren H, Chen X, Lv L, He D, Zhou H, Liang Z, Liu JH, Shen J. Emergence of plasmid-mediated colistin resistance mechanism MCR-1 in animals and human beings in China: a microbiological and molecular biological study. Lancet Infect Dis. 2016;16:161-8.

24. Baron S, Hadjadj L, Rolain JM, Olaitan AO. Molecular mechanisms of polymixine resistance: knows and unknowns. Int J Antimicrob Agents. 2016:48:583-91.

25. Malhotra-Kumar S, Xavier BB, Das AJ, Lammens C, Hoang HTT, Pham NT, Goossens $\mathrm{H}$. Colistin-resistant Escherichia coli harbouring mcr-1 isolated from food animals in Hanoi, Vietnam. Lancet Infect Dis. 2016;16:286-7.

26. Burow E, Simoneit C, Tenhagen BA, Kasbohrer A. Oral antimicrobials increase antimicrobial resistance in porcine E. coli - a systematic review. Prev Vet Med. 2014:113:364-75.

27. Maes D, Deluyker H, Verdonck M, Castryck F, Miry C, Vrijes B, de Kruif A. Herd factors associated with the seroprevalences of four major respiratory pathogens in slaughter pigs from farrow-to-finish pig herds. Vet Res. 2000;31:313-27. 
28. Thamlikitkul V, Rattanaumpawan P, Boonyasiri A, Pumsuwan V, Judaeng T, Tiengrim S, Paveenkittiporn W, Rojanasthien S, Jaroenpoj S,

Issaracharnvanich S. Thailand antimicrobial resistance containment and prevention program. J Glob Antimicrob Resist. 2015;3:290-4.

29. Callens B, Faes C, Maes D, Catry B, Boyen F, Francoys D, de Jong E, Haesebrouck F, Dewulf J. Presence of antimicrobial resistance and antimicrobial use in sows are risk factors for antimicrobial resistance in their offspring. Microb Drug Resist. 2015;21:50-8.

30. EFSA (European Food Safety Authority). Manual for reporting on antimicrobial resistance within the framework of directive 2003/99/EC and decision 2013/ 652/EU for information deriving from the year 2015. In: EFSA supporting publication 2016:EN-990; 2016. p. 35.

31. Central Ethical Review Board, Sweden, 2017. http://www.epn.se/en/start/ the-organisation/ Accessed July 22017.

Submit your next manuscript to BioMed Central and we will help you at every step:

- We accept pre-submission inquiries

- Our selector tool helps you to find the most relevant journal

- We provide round the clock customer support

- Convenient online submission

- Thorough peer review

- Inclusion in PubMed and all major indexing services

- Maximum visibility for your research

Submit your manuscript at www.biomedcentral.com/submit
Biomed Central 